\title{
Energy efficiency of cogeneration utilization of residual heat of flue gases during the drying of coal concentrate in pipe-dryers
}

\author{
Yurii Oksen ${ }^{1, *}$, Maksym Radiuk ${ }^{1}$, Yurii Komissarov ${ }^{1}$, and Mykhailo Kirsanov ${ }^{2}$ \\ ${ }^{1}$ National Technical University "Dniprovska Politechnika”, 49005, Dnipro, Yavornytskoho Ave., 19, \\ Ukraine \\ ${ }^{2}$ Institute of Geotechnical Mechanics named by N. Poljakov of National Academy of Sciences of \\ Ukraine, 49005, Dnipro, Simferopolska Str., 2a, Ukraine
}

\begin{abstract}
The possibility of increasing the efficiency of drying coal concentrate unit on the basis of pipe-dryers has been investigated by converting the heat of flue gases outlet into electrical energy and the heat potential of hot water supply system with a heat power generation unit operating on low-boiling working fluids. A method and an algorithm for calculating the thermal mode of the unit under the conditions of specified limitations on temperature pressures in heat exchangers have been developed. On the basis of mathematical modeling of thermal conditions, it has been found that under the conditions of PD-11 pipe-dryers, when the heat power generation unit operates with butane-pentane mixture, $204 \mathrm{~kW}$ of electricity can be generated with the condensation cycle, and $1780 \mathrm{~kW}$ of heat and $65 \mathrm{~kW}$ of electric energy can be generated with the heating cycle.
\end{abstract}

\section{Introduction}

In the coal preparation and coal briquette factories, pipe-dryers are widely used for drying coal concentrate and fine product with a grain size of up to $13-15 \mathrm{~mm}[1,2]$. In these devices, the concentrate particles are picked up by a stream of hot flue gases and moved along with them, while in suspension. The large contact surface, the temperature difference and the concentration of water vapor in the gases and the dried material provide high intensity evaporation of moisture. Installations on the basis of pipe-dryers are characterized by simplicity of design and high performance, but they are also characterized by high energy intensity. It is possible to increase the efficiency of installations by utilizing the residual heat of the leaving flue gases. Utilization of waste low-grade heat in Ukraine is currently receiving much attention $[3-6]$.

The purpose of this study is to determine the energy efficiency indicators of utilizing the residual heat of flue gases by converting it into electrical energy and heat for the heat supply of an enterprise.

\footnotetext{
${ }^{*}$ Corresponding author: oksenui49@gmail.com
} 


\section{Methods}

The temperature of the flue gases at the outlet of the drying units is $100-130{ }^{\circ} \mathrm{C}$. The conversion of heat of such a potential into mechanical work and electrical energy is possible with the help of a power generation unit (PGU) operating on low-boiling working fluids according to the Rankine cycle. Schematic diagram of PGU is shown in Figure 1. Its main elements are as follows, steam generator SG, turbine $\mathrm{T}$ with electric generator $\mathrm{EG}$, condenser $\mathrm{C}$, water heater WH of hot water supply network, pumps P1 and P2.

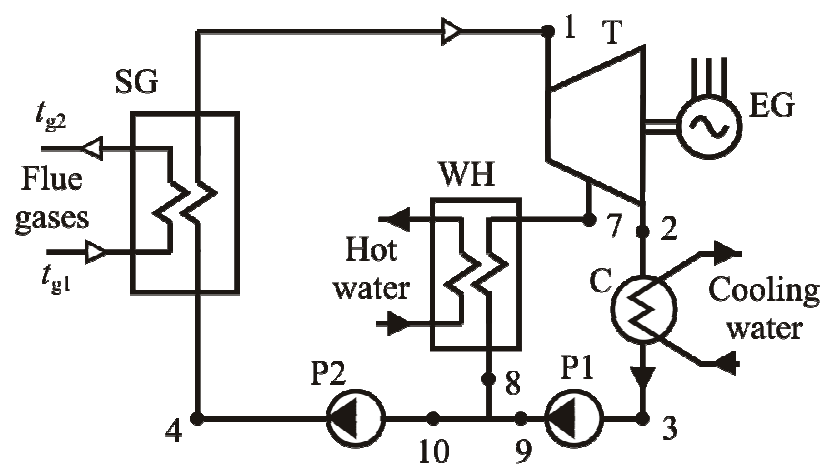

Fig. 1. Schematic diagram of power generation unit: $\mathrm{T}$ - turbine; $\mathrm{EG}$ - electric generator; $\mathrm{C}-$ condenser; P1, P2 - pumps; SG - steam generator; $\mathrm{WH}$ - water heater for hot water supply system.

Thermodynamic cycle of power generation unit (Rankine cycle) in $T, s$-coordinates ( $T$ - temperature, $s$ - entropy) is shown in Figure 2.

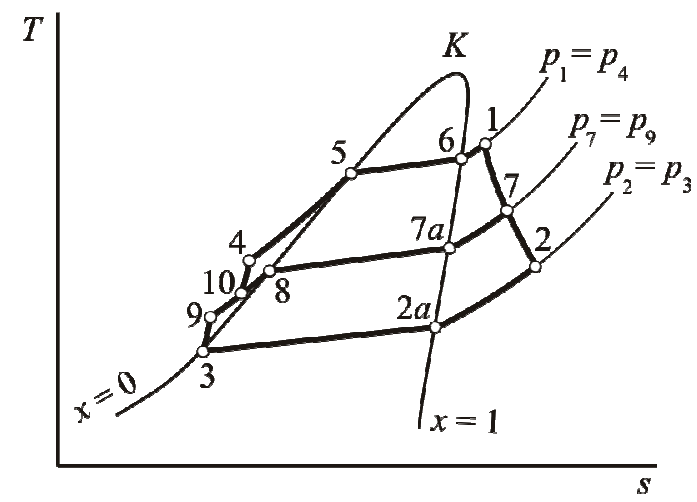

Fig. 2. Thermodynamic cycle of power generation unit.

The cycle is shown against the background of the phase diagram of the state of the working fluid, for which the derivative is on the upper boundary curve (degree of dryness $x=1)(\partial T / \partial s)_{x=1}>0$. The numbers of the cycle points correspond to the numbers of the points on the diagram of PGU. The processes of changing the state of low-boiling working fluid in heat exchangers are assumed isobaric and in the turbine and pumps as adiabatic with internal friction.

The working fluid enters the vapor generator in the liquid phase (point 4). Due to the heat received from the flue gases, it is heated to the boiling state (point 5), then it goes into the state of dry saturated vapor (point 6) and can overheat (point 1). In the turbine, the lowboiling working fluid vapor expands and does the work that is transformed by electrical generator into electrical energy (process 1-7-2). The turbine consists of two stages of expansion - high and low pressure. After expansion in the high-pressure stage, a part of the 
vapor with the state of point 7 can be sent from the intermediate selection to the water heater for the hot water supply system. The remainder of the vapor, after expansion in the low pressure stage, is directed to the condenser. In the water heater and condenser, the working fluid is cooled to saturation state (7-7a and 2-2a processes) and then condensed ( $7 a-8$ and $2 a-3$ processes), giving off heat, respectively, to the water heated for the hot water supply system and cooling water, and then goes into the environment. Low-boiling working fluid condensate is pumped to a vapor generator using pumps.

Thus, the scheme allows the implementation of condensation and cogeneration modes of PGU. In the absence of the need for hot water, the condensation cycle 1-2-3-4-1 is used, which is characterized by maximum power generation. The heating cycle 1-7-8-10-4-1 (without passing the working fluid to the condenser) is characterized by maximum hot water generation. The change in the ratio between the vapor consumption for the heater and the condenser provides the flexibility to regulate PGU modes depending on the need for hot water.

When simulating PGU modes, the vapor expansion process in the turbine was assumed such that either at its inlet or at the outlet, the low-boiling working fluid vapor was dry and saturated. This choice of parameters provides the maximum efficiency of heat conversion into work and electrical energy [7].

It can be stated from Figure 2 that the power generation unit cycle characterized by three levels of pressure, such as the minimum, $p_{2}=p_{2 a}=p_{3}$, which is determined by the condensation temperature of the low-boiling working fluid (LBWF) vapor in the condenser $t_{3}$, the pressure in the intermediate selection $p_{7}=p_{7 a}=p_{8}$, which is determined by the condensation temperature of the vapor in the water heater $t_{8}$, and the maximum pressure of the vapor in the inlet of the turbine $p_{1}=p_{6}=p_{5}=p_{4}$, determined by average temperature of the vapor generator. To ensure maximum thermal efficiency of the cycle, it should be as close as possible to the temperature of the heat source - flue gases. It can be seen from Figure 3 that the closest approximation of the graphs of changes in the temperatures of the low-boiling working fluid and flue gases along the heat exchange surface $F$ will be in the cross section of the vapor generator, in which the low-boiling working fluid boils and its state is determined by point 5 of the cycle.

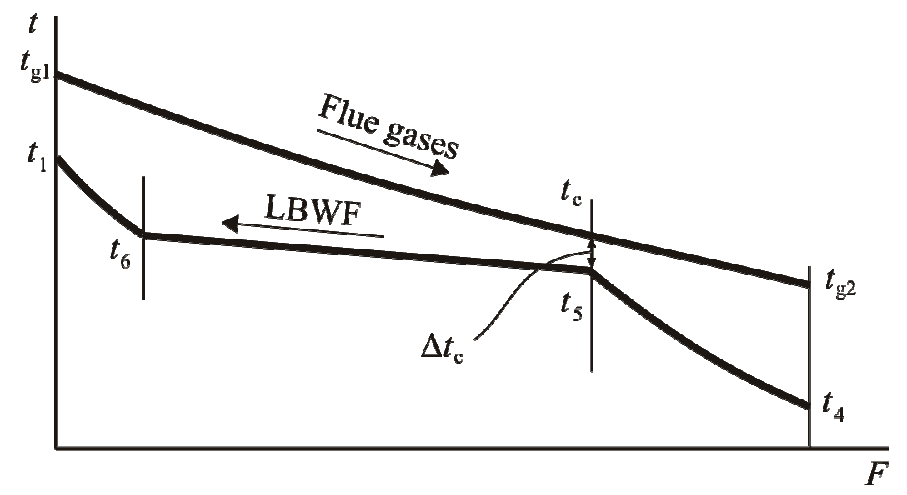

Fig. 3. Flue gases and low-boiling working fluid temperature changes in vapor generator.

This section is called critical, and the temperature of the flue gases in it is critical $t_{\mathrm{c}}$. The specified temperature difference in the critical section $\Delta t_{\mathrm{c}}$ will determine the given approximation of the temperature graphs of the low-boiling working fluid and flue gases and the corresponding values of temperatures $t_{5}$ and $t_{\mathrm{c}}$. The latter can be calculated from the equations of heat balance of the section of the vapor generator, on which the liquid lowboiling working fluid is heated to the boiling state, and the vapor generator as a whole.

The main energy indicators of the power generation unit were calculated using the 
following formulas:

$$
\begin{aligned}
& Q_{\mathrm{ut}}=G c_{\mathrm{p}}\left(t_{\mathrm{g} 1}-t_{\mathrm{g} 2}\right), \\
& q_{\mathrm{ut}}=h_{1}-h_{4}, \\
& G=\frac{Q_{\mathrm{ut}}}{q_{\mathrm{ut}}} \\
& Q_{\mathrm{h}}=G a\left(h_{7}-h_{8}\right), \\
& N_{\mathrm{t}}=G\left(h_{1}-h_{7}\right)+G(1-a)\left(h_{7}-h_{2}\right), \\
& N_{\mathrm{p}}=G\left(h_{4}-h_{10}\right)+G(1-a)\left(h_{9}-h_{3}\right), \\
& N_{\mathrm{el}}=N_{\mathrm{t}} \eta_{\mathrm{tmech}} \eta_{\mathrm{eg}}-\frac{N_{\mathrm{p}}}{\eta_{\mathrm{pmech}} \eta_{\mathrm{em}}}, \\
& \eta_{\mathrm{el}}=\frac{N_{\mathrm{el}}}{Q_{\mathrm{ut}}}, \\
& \eta_{\text {full }}=\frac{N_{\mathrm{el}}+Q_{\mathrm{h}}}{Q_{\mathrm{ut}}},
\end{aligned}
$$

where $Q_{\mathrm{ut}}-$ utilized heat power, $\mathrm{kW} ; Q_{\mathrm{h}}-$ heat power for hot water, $\mathrm{kW} ; c_{\mathrm{p}}-$ specific heat at constant pressure of flue gases, $\mathrm{kJ} /(\mathrm{kg} \cdot \mathrm{K}) ; t_{\mathrm{g} 1}$ and $t_{\mathrm{g} 2}-$ inlet and outlet temperature of flue gases, ${ }^{\circ} \mathrm{C} ; q_{\mathrm{ut}}$ - specific heat supplied to the low-boiling working fluid in the vapor generator, $\mathrm{kJ} / \mathrm{kg} ; G$ - working fluid mass flow rate, $\mathrm{kg} / \mathrm{s} ; h_{1}, h_{2}, h_{3}, h_{4}, h_{7}, h_{8}, h_{9}, h_{10}$, working fluid enthalpy in the corresponding points of the cycle, $\mathrm{kJ} / \mathrm{kg} ; a$ - mass fraction of the working fluid vapor, directed from the output of the first stage of the turbine to the grid heater; $N_{\mathrm{t}}$ and $N_{\mathrm{p}}$ - internal power of the turbine and pumps, $\mathrm{kW} ; N_{\mathrm{el}}-$ electrical power generated, $\mathrm{kW} ; \eta_{\mathrm{t} \text { mech }}$ and $\eta_{\mathrm{p} \text { mech }}-$ mechanical efficiencies of the turbine and pumps; $\eta_{\mathrm{eg}}$, $\eta_{\mathrm{em}}$ - efficiency of the electric generator and electric motors; $\eta_{\mathrm{el}}-$ efficiency of PGU running in electrical power generation mode; $\eta_{\text {full }}-$ heat recovery efficiency of flue gases heat.

\section{Results and discussion}

The thermal model of PGU have been modeled with the initial data which are as follows: flue gas volume flow rate is $22.5 \mathrm{~m}^{3} / \mathrm{s}$, which corresponds to the nominal value for the PD-11 pipe dryer; the initial temperature of the flue gases is $130{ }^{\circ} \mathrm{C}$; the condensation temperature of the low-boiling working fluid in the condenser is $30^{\circ} \mathrm{C}$; in the water heater for the hot water supply system is $55^{\circ} \mathrm{C}$; the minimum temperature pressure at the outlet of heat exchangers is $10{ }^{\circ} \mathrm{C}$; isentropic and mechanical turbine efficiency are 0.7 and 0.9 ; efficiency of the electric generator is 0.97 ; isentropic and mechanical efficiency of pumps are 0.7 and 0.97 respectively; efficiency of electric motors of pumps is 0.97 . The final temperature of the flue gases in different design options ranged from 60 to $80{ }^{\circ} \mathrm{C}$. The working substances also varied, in which R236ea, n-pentane, isobutane, butane, neopentane and butane-pentane mixture were considered in a ratio of $0.5 / 0.5$ by mass fraction. 
The effect of the temperature of the flue gases after the vapor generator on the amount of generated electrical power has been investigated for the case of operation of PGU in the condensation mode. On the bases of simulation the diagrams Figure 4 and 5 have been drawn.

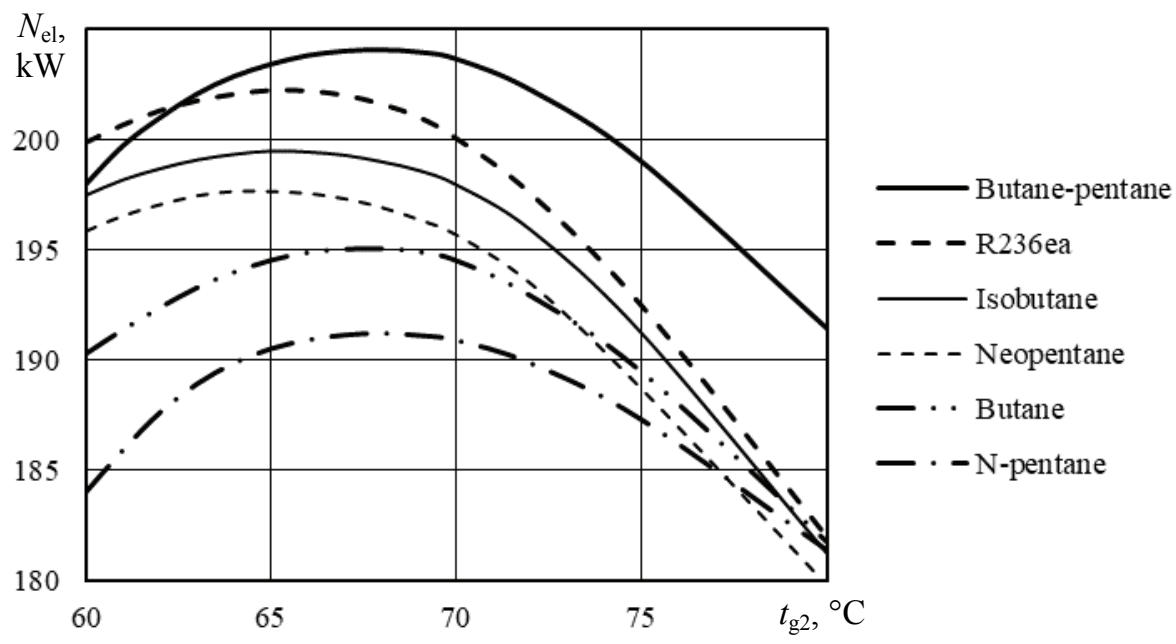

Fig. 4. Variation of electrical power produced by power generation unit with different working fluids with various flue gases outlet temperature.

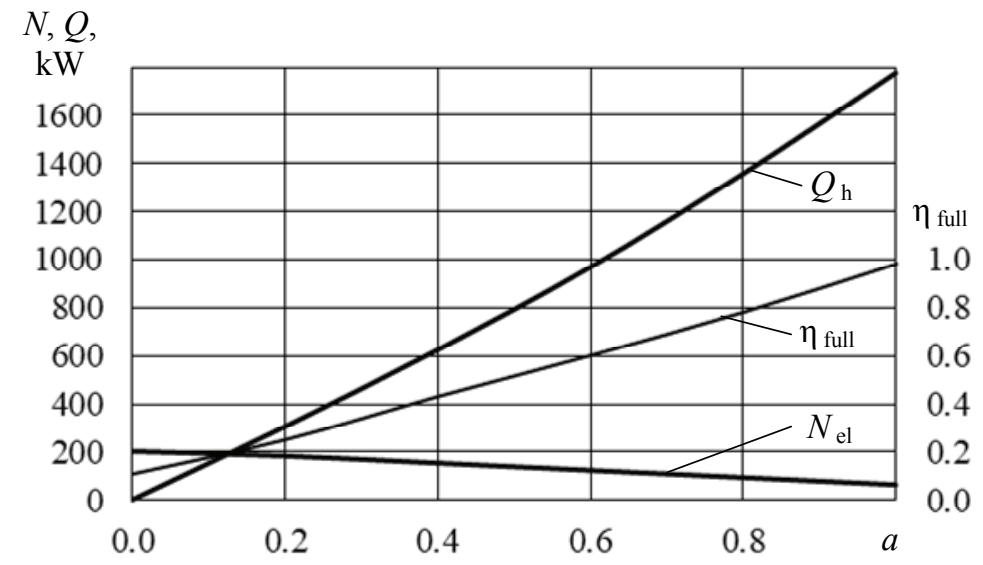

Fig. 5. Variation of generated heat $Q_{\mathrm{h}}$, electric power $N_{\mathrm{el}}$ and heat recovery efficiency of utilized heat $\eta_{\text {full }}$ with various vapor extraction rate $a$.

The diagrams (Fig. 4) show the influence of the final temperature of the flue gases on the generated electrical power $N_{\mathrm{el}}=f\left(t_{\mathrm{g} 2}\right)$ using various working fluids.

It can be seen from the figure that the dependence $N_{\mathrm{el}}=f\left(t_{\mathrm{g} 2}\right)$ has a maximum at a finite temperature of flue gases of $65-68{ }^{\circ} \mathrm{C}$. The presence of the maximum is explained by the opposite effect of the temperature $t_{\mathrm{g} 2}$ on the amount of utilized thermal power and the efficiency of its conversion into electricity. It also follows from the figure that the electric power generated by PGU when using the mixed working fluid butane-pentane will be higher than in the case of using each pure component separately and higher than in the case of using other considered working substances.

Figure 5 illustrates the variation of generated heat $Q_{\mathrm{h}}$ and electric power $N_{\mathrm{el}}$, as well as heat recovery efficiency of utilized heat $\eta_{\text {full }}$ with various vapor extraction rate $a$ when PGU 
runs with butane-propane mixture in heating mode and at the final gas temperature equals to $t_{\mathrm{g} 2}=68{ }^{\circ} \mathrm{C}$.

It can be observed that electrical efficiency slightly decreases as vapor extraction rate increases. However, the amount of heat transferred to the hot water supply system increases significantly. It leads to an increase in the overall recovery efficiency of the residual heat of flue gases.

\section{Conclusions}

A mathematical model of cogeneration utilization of residual low-grade heat of flue gases for the generation of electrical and thermal energy in the power generation unit with lowboiling working fluid has been developed. On the basis of mathematical modeling of thermal modes of PGU, the following have been stated:

- the variation of generated electrical power with the final temperature of the flue gases has maximum at the temperature range from 65 to $68^{\circ} \mathrm{C}$;

- when the power generation unit operates in a condensation mode with a butanepentane mixture $(0.5 / 0.5)$ as a working fluid, $204 \mathrm{~kW}$ of electrical power with an efficiency of electricity generation of $10.8 \%$ can be obtained;

- in the case of the operation of PGU in a purely heating mode with the generation of hot water with a temperature of $50{ }^{\circ} \mathrm{C}$, the value of the thermal power produced will be $1780 \mathrm{~kW}$, the electric power is $65 \mathrm{~kW}$, and heat recovery efficiency of flue gases heat is close to 1.0 .

The results obtained show a fairly high energy efficiency of cogeneration utilization of residual heat of exhaust flue gases and the promising practical implementation of this direction of improving the efficiency of coal concentrate drying plants.

\section{References}

1. Blagov, I., Kotkin, A., Zarubin, L. (1984). Spravochnik po obogashcheniyu ugley. Moskva: Nedra

2. Rudenko, K. Shemakhanov, M. (1984). Obezvozhivaniye i pyleulavlivaniye. Moskva: Nedra

3. Bulat, A., Chemeris, I. (2006). Nauchno-tekhnicheskiye osnovy sozdaniya shakhtnykh kogeneratsionnykh energeticheskikh kompleksov. Kyiv: Naukova dumka

4. Pivnyak, G., Samusia, V., Oksen, Y., Radiuk, M. (2014). Parameters optimization of heat pump units in mining enterprises. Progressive technologies of coal, coalbed methane and ores mining, 19-24

5. Oksen, Y., Samusia, O. (2014). Economic efficiency of heat pump technology for geothermal heat recovery from mine water. Progressive technologies of coal, coalbed methane, and ores mining, 191-194

6. Pivnyak, G., Samusia, V., Oksen, Y., Radiuk, M. (2015). Efficiency increase of heat pump technology for waste heat recovery in coal mines. New Developments in Mining Engineering: Theoretical and Practical Solutions of Mineral Resources Mining, 1-4

7. Oksen, Yu.I., Radiuk, M.V. (2009). Investigation effectiveness of the use of secondary heat gas piston installations for electricity generation. Geotekhnicheskaya Mekhanika [Geo-technical Mechanics], 81, 200-207 